School-related anxiety symptomatology in a community sample of primaryschool-aged children on the autism spectrum

Accepted into Journal of School Psychology

\author{
Dawn Adams ${ }^{1,2}$ Kate Simpson ${ }^{1,2} \&$ Deb Keen ${ }^{1,2}$ \\ ${ }^{1}$ Autism Centre of Excellence, Griffith University, Australia \\ ${ }^{2}$ Cooperative Research Centre for Living with Autism (Autism CRC), Australia
}

Corresponding author:

Dawn Adams, Autism Centre of Excellence, School of Education and Professional Studies, Griffith University, Messines Ridge Road, Mt Gravatt, Brisbane, QLD 4122, Australia

Email: Dawn.Adams@griffith.edu.au 


\begin{abstract}
Although it is recognised that the prevalence of anxiety is elevated in children with autism spectrum disorder, there has been very limited research exploring such anxiety in school contexts. As a result, there is limited detailed information for teachers or educators on how anxiety in autism may present in the school setting for children on the autism spectrum. The aims of this study were to (a) report the profile of results on a measure of school anxiety in a community sample of children on the autism spectrum, (b) investigate whether scores on this measure differed with child variables or enrollment into a mainstream or special school, and (c) document the level of agreement between teacher-reported and parent-reported anxiety symptoms. Teachers of 92 children aged 5-12 completed a questionnaire pack including the School Anxiety Scale-Teacher Rating (SAS-TR). Elevated levels of anxiety (above the SASTR total anxiety clinical cut-off) were noted in $21.7 \%$ of the sample, with a larger proportion of children scoring above the generalised anxiety cut-off (27.2\%) than the social anxiety cut-off (14.1\%). Older participants $\left(U=744, p=.02, \eta^{2}=.06\right)$ and those attending mainstream schools $\left(U=661, p=.02, \eta^{2}=.06\right)$ had significantly higher scores on the generalized, but not the social, anxiety subscales, with effect sizes suggesting a medium effect. The results highlight the need for further, more detailed research into the presentation and impact of school anxiety in children with autism attending both mainstream and special schools.
\end{abstract}

Keywords: Autism, anxiety, teacher, parent, questionnaire 


\section{School-related anxiety symptomatology in a community sample of primary- school-aged children on the autism spectrum}

Autism spectrum disorder is a neurodevelopmental disorder characterized by impairments in reciprocal social communication and interaction, and individualized patterns of repetitive and restrictive behavior (American Psychiatric Association, 2013). Recent estimates place the prevalence of autism at 1 in 68 children (Centers for Disease Control and Prevention, 2014). It is now recognized that one of the most prevalent mental health disorders in children, anxiety disorders, are even more common in children on the autism spectrum ${ }^{1}$. Meta-analyses place the prevalence of anxiety in autism at around 40\% (van Steensel, Bogels, \& Perrin, 2011), compared to $13.4 \%$ of children worldwide without autism (Polanczyk, Salum, Sugaya, Caye, \& Rohde, 2015).

\section{Autism and anxiety in educational settings}

It is well documented that anxiety can have a serious impact on the school experience of children without autism, being associated with poor academic achievement, poorer adaptive outcomes (Langley, Bergman, McCracken, \& Piacentini, 2004), increased school refusal (Mychailyszyn, Mendez, \& Kendall, 2010), and reduced engagement and attainment in both academic and social aspects of school life (Weissman, Antinoro, \& Chu, 2009). Whilst there is only limited research focusing upon anxiety and outcomes in autism, it is evident that the presence of anxiety combined with the profile of autism characteristics is likely to significantly reduce an individual's ability to successfully meet and cope with school-related

\footnotetext{
${ }^{1}$ The term "on the autism spectrum" is used in concordance with preferences of individuals on the autism spectrum, their parents and professionals working in this area (Kenny et al., 2016).
} 
expectations (Ashburner, Ziviani, \& Rodger, 2010; Ferraioli \& Harris, 2011; Fujii et al., 2013).

Despite the high prevalence of anxiety in children on the autism spectrum, there is scant research that has investigated anxiety in students on the autism spectrum in school contexts. The school context, including environmental, social, and academic factors, has been identified as contributing to stress and anxiety in children on the autism spectrum (review Roberts \& Simpson, 2016). High school students on the autism spectrum describe experiencing anxiety in social situations particularly during unstructured periods, and difficulties dealing with uncertainties during the school day (Hebron \& Humphrey, 2014). This corresponds with both social anxiety and generalized anxiety being identified as common co-existing psychiatric conditions in school-aged children on the autism spectrum (Simonoff et al., 2008). Social anxiety is related to social functioning difficulties (Chang, Quan, \& Wood, 2012) while generalized anxiety, characterized by excessive worrying about events and activities, is less related to social competence in children on the autism spectrum (Johnston \& Iarocci, 2017). Both generalized and social anxiety have been shown to increase with age (Johnston \& Iarocci, 2017; Kuusikko et al., 2008). Understanding anxiety in children on the autism spectrum, within the school context, is critical to developing supports and identifying strategies to ameliorate school factors which may impact on the mental health of these children.

Surprisingly few studies have included teacher-reported symptoms of anxiety. One systematic review of anxiety in autism identified only three studies with both parent and teacher ratings of anxiety (van Steensel et al., 2011). Where teacher reports on anxiety have been included, few have used anxiety-specific measures, relying instead on mean subscale or total scores from measures aimed at describing a 
broad range of emotional and/or behavioral presentations (e.g., Developmental Behaviour Checklist for teachers, Einfeld \& Tonge, 2002; Strengths and Difficulties Questionnaire for teachers, Goodman, 1997). As a result, there is limited detailed information on how anxiety in autism may present in the school setting for children on the autism spectrum, and how this may be similar to or different from that noted at home.

\section{Inter-informant agreement on measures of anxiety in autism}

Using a multi-informant assessment approach (Kraemer et al., 2003) that considers reports from informants who observe the individual in different contexts (e.g., home vs. school) can yield a more comprehensive picture of symptomatology that may vary across different contexts (Stratis \& Lecavalier, 2015). Different informants may also interact differently with the individual, or have different expectations, standards, or experience of working with individuals with autism and/or anxiety. These factors can impact upon the topography and frequency of the symptomatology observed as well as on the way observers rate these on standardized checklists. Both informant agreements and discrepancies can impact assessment, classification, and treatment of the presenting disorder (Beesdo, Knappe, \& Pine, 2009; Herzig-Anderson, Colognori, Fox, Stewart, \& Masia Warner, 2012). However, multi-informant approaches are only useful if each informant is considered to have valid information to provide and is provided with reliable methods to share such information (see discussion in De Los Reyes et al., 2015).

Repeated meta-analyses on data from typically developing children highlight that informant-agreement levels are lower on internalizing than externalizing disorders (Achenbach, McConaughy, \& Howell, 1987; De Los Reyes et al., 2015). Discrepancies between informant reports of externalizing versus internalizing 
disorders such as anxiety may be even more pronounced in children on the autism spectrum, given the difficulties in recognizing anxiety in these children. Low interinformant agreement levels have been reported for internalizing disorders in autism (Stratis \& Lecavalier, 2015). Studies reporting low correlations between parent and teacher ratings for anxiety in autism (e.g., Kanne, Abbacchi, \& Constantino, 2009) suggest the low levels of agreement may not simply be a scaling issue (i.e., one informant rating consistently lower than the other) but that informants are reporting different patterns in these different contexts. Explanations for this low agreement level include the attribution bias context model (De Los Reyes \& Kazdin, 2005), informant bias (Hoyt, 2000), and differing presentation due to differences in the cognitive and social demands between settings (Allen \& Lerman, 2017). Comparisons of group mean average scores or between informants may provide an indication of whether the overall level of anxiety is similar between informants and/or contexts, but such comparisons do not answer the potentially more interesting clinical question of whether the same symptoms of anxiety are noted by informants at the same levels across contexts.

To our knowledge, only two studies to date have reported item-level teacher and parent data for anxiety symptomatology in children on the autism spectrum. Guttmann-Steinmetz, Gadow, DeVincent, and Crowell (2010) reported mean group scores for individual items from the parent and teacher versions of the Child Symptom Inventory 4th Edition (CSI-4; Gadow \& Sprafkin, 2002). However, they did not explore agreement between the parent and teacher ratings. Weisbrot, Gadow, DeVincent, and Pomeroy (2005) reported item-level data from the CSI-4 from 272 parents and 268 children with pervasive developmental disorders (PDD). They observed group means for each item and concluded that teachers provided higher 
ratings than parents for two general anxiety items (unable to relax, low energy level), but that parents provided higher ratings than teachers for specific phobia items, although no comparisons of ratings were made. Both studies used the CSI-4, a measure of emotional/behavioral factors, rather than an anxiety-specific measure that could potentially yield more detailed data on anxiety symptomatology with their samples. This highlights the need for further work with anxiety-specific questionnaires that would enable exploration of differences and similarities between parent and teacher observations of anxiety symptoms and their frequency.

In summary, to date there has been limited research exploring teacher-reported levels of school anxiety in children on the autism spectrum, and those who use teacher data are mainly reporting means of subscales or total scores from non-anxiety-specific measures. Such research is important, as research with typically developing children show that if anxiety is unrecognized and therefore left untreated, it can impact upon a child's educational performance (e.g., recall of academic knowledge, poorer academic grades, lower overall school performance; Langley et al., 2004; Ma, 1999) as well as their social outcomes (e.g., peer relationships; Langley et al., 2004).

\section{The present study}

The aims of the current study were to explore the profile of scores on a measure of school anxiety across a community sample of children on the autism spectrum and to document the level of agreement between items on the teacherreported measure of the school anxiety scale and a parent-completed report of anxiety symptoms.

The following research questions were posed:

(1) What is the profile of scores on a measure of school anxiety in a sample of children on the autism spectrum? 
(2) Do scores on this measure of school anxiety differ based upon child variables (age, gender, autism characteristics) or educational placement (mainstream/secondary)?

(3) Is there agreement between parent and teacher ratings of anxiety-related symptomatology within the home and school setting at (i) subscale, and (ii) item level?

\section{Methods}

This study used data collected as part of the Longitudinal study of Australian Students with Autism (LASA). Ethical approval for this study was obtained from all participating universities and health authorities.

\section{Recruitment procedures}

The full recruitment procedure for the larger LASA study is described in Roberts et al. (2018) In brief, parents of autistic children aged 4-5 or 9-10 years living in Australia were invited through clinics and advertisements on social media to take part in a longitudinal study over 6 years, focusing upon child participation and educational outcomes for children on the autism spectrum. The age ranges for this larger cross-sequential study were chosen for two reasons: firstly, to ensure that data collection occurred over two critical transition periods - starting school and moving from primary to high school; secondly, to allow for a comparison of children aged 910 years on the autism spectrum at Time 1 (older cohort) and those aged 9-10 years at Time 6 (younger cohort).

All participants were requested to provide copies of their diagnostic reports as well as to complete a measure of autism characteristics (Social Communication Questionnaire [SCQ]; Rutter, Bailey, Lord, \& Berument, 2003) to confirm diagnosis. 
Data collection from schools began in the second year of the longitudinal study. If parents consented to information being collected from their child's school, principals and teachers were invited to complete an online questionnaire survey. First, this study focused on data provided by the child's teacher to explore the presentation of anxiety in school settings. Parent and teacher data collected during the second year of the longitudinal study were then used to explore whether there was an association between levels of anxiety reported at home and those reported at school.

\section{Participants}

A total of 211 parents gave consent for the study team to contact their child's school. Consent was gained from principals before teachers were contacted. Each principal was contacted by telephone (and follow-up emails) and invited to participate. Of those who spoke to members of the research team, 122 (57.8\%) expressed interest in their school participating in the study and consented to the teacher receiving an invitation to participate. In total, 99 teachers completed the online questionnaire. Data from two participants were excluded as the child was individually home-schooled or tutored, and one participant was removed due to more than $25 \%$ of the data being incomplete within the teacher questionnaire. Four further participants were excluded as their SCQ score was below the recommended cut-off score of 11 (Lee, David, Rusyniak, Landa, \& Newschaffer, 2007) and no diagnostic report (from a pediatrician or psychologist) was provided.

After exclusions, the sample consisted of data on 92 children with a community diagnosis of autism, living in Australia, and attending inclusive mainstream (67.4\%) or special education (32.6\%) primary settings. The sample was predominantly male (80.4\%) and due to the study design, children were all aged 
between 5-7 years (60-90 months, $n=41)$ or 9-12 years (118-149 months, $n=51)$ at the time the teacher questionnaire was completed. Almost one-third (32.6\%) of the sample reported a gross annual family income below the median household income of Australia of $\$ 80,000,53.5 \%$ reported annual family income of $\$ 80,000-\$ 180,000$, 8.7\% reported an annual family income in excess of $\$ 180,000$, and five families (5.4\%) decline to provide information on family income.

Forty parents reported that their child has diagnoses in addition to their diagnosis of being on the autism spectrum. Fifteen (16.3\%) children were reported to have a diagnosis of Attention-Deficit/Hyperactivity Disorder (ADHD), eight (9.8\%) a diagnosis of anxiety (of whom five were reported to be prescribed selective serotonin reuptake inhibitors, SSRIs), five (5.4\%) Oppositional Defiant Disorder (ODD; of whom four also had a diagnosis of ADHD), and three (3.3\%) a diagnosis of asthma. Parents reported the age at which their child received their formal autism diagnosis, with the most children being diagnosed at age 2 (18.4\%), 3 (14.1\%), 4 (22.8\%), or 5 years of age (15.3\%). Seventeen children (18.4\%) received their diagnosis aged 6-7 and nine children (9.8\%) aged eight or above.

Teacher informants were predominantly female (89.1\%), employed full-time (88.9\%), and educated to degree level (76.1\%). All described themselves as class teachers or special education teachers and had between one and 41 years' experience of teaching (average 11.3 years). Teachers reported having the child in their class for between 2 and 73 months (average 10.4 months). Class sizes for the mainstream schools ranged from $13-45(\bar{x}=24.2, S D=4.85)$ and for the special education classrooms from 4-27 ( $\bar{x}=9.47, S D=6.30)$. Within the mainstream classrooms, teachers reported that between one and 10 children in their class had an additional 
diagnosis of an intellectual, developmental, or physical disability and/or a diagnosis on the autism spectrum $(\bar{x}=2.72, S D=1.90)$.

Parent informants were mostly mothers (90.2\%) and no respondents reported living separately from the child. Due to teaching commitments or needing time to get to know the child in the classroom in order to complete the questionnaires, the time between teachers and parents completing the questionnaires ranged from 0 to 8 months, with a mean average of 3.20 months (SD 2.67).

\section{Measures}

Demographic characteristics. These were collected using a parent questionnaire focusing upon child (age, gender, age at diagnosis), parent (education, employment), and household (income) variables. Teachers were asked about their teaching experience (e.g., primary degree, length of time teaching) and how many months they had known the child, and were asked questions about their school setting (e.g., mainstream, special education, etc.).

Autism characteristics. The Social Communication Questionnaire (SCQ) (Rutter et al., 2003) is a behavioral checklist that requires parents to indicate the presence of certain social, communicative, or stereotyped behaviors by answering yes or no to 40 items. The SCQ has been extensively researched, with a recent metaanalysis (Chesnut, Wei, Barnard-Brak, \& Richman, 2016) concluding that it is an acceptable screening measure for autism spectrum disorder (area under the curve .89) if used within the correct age range. A higher score represents a higher number of behaviors which may be considered indicative of autism.

Teacher-rated child anxiety. The School Anxiety Scale - Teacher Report (SAS-TR; Lyneham, Street, Abbott, \& Rapee, 2008) is a measure of behaviors and feelings "distinctive to the experience of anxiety" in children 5-12 years old. It was 
derived from a combination of established measures of anxiety and input from experienced clinical psychologists with the aim of creating a scale that is based upon symptoms that are observable within the classroom setting. The authors report good validity against established measures of anxiety within clinical samples of children with elevated anxiety and good test-retest reliability. It consists of 16 items which can be summed into a total score or separated into those focusing upon generalized anxiety (9 items) or social anxiety (7 items). The authors recommend "high-anxiety" cut-offs to discriminate between those with and without anxiety of 17 or above for the total score, 10 or above for the general anxiety subscale, and 8 or above for the social anxiety subscale. These cut-off scores were based upon the top $20 \%$ of scores from a community (non-clinical) sample of 280 children. These cut-offs placed $68.8 \%$ of children in a clinical sample of children receiving treatment at a specialist anxiety research clinic within the "clinical” range (Lyneham et al., 2008). Lyneham et al. (2008) also explored pre- to post-treatment group means, noting that following treatment, children dropped from a pre-treatment mean within the clinical range of 18.57 (SD 11.19) to a post-treatment mean of 14.47 (SD 8.74), which is below the clinical range.

The SAS-TR has been used as an outcome measure in one study exploring cognitive behavioral therapy for anxiety in adolescents on the autism spectrum (Luxford, Hadwin, \& Kovshoff, 2016) where children who received the intervention had a group mean score in the clinical range (28.61, SD 7.81) before the intervention to a group mean score within the non-clinical range (14.39, SD 7.74) after the intervention was complete. Cronbach's alpha for this measure within the current sample is good for all scores, with $\alpha=.89$ for the total score, $\alpha=.84$ for the general anxiety subscale, and $\alpha=.86$ for the social subscale. 
Given that SAS-TR development paper (Lyneham et al., 2008) reported correlated subscales, and in recognition that this measure has not been widely used with children on the autism spectrum, it was deemed appropriate to calculate the proportional reduction in mean square error (PRMSE) for subscale values to explore the value of reporting at subscale level (as per Haberman, 2008). PRMSEтот values were calculated as per Reise, Bonifay and Haviland (2013) and compared to PRMSEs values for each subscale. The degree that the PRMSEs are larger than the PRMSE $\mathrm{POT}_{\mathrm{T}}$ subscale scores provide a relatively better indicator of subscale true score standing, and, thus, can be reported. For both subscales, the PRMSEs values (General Anxiety $=.84$, Social Anxiety = .86) were larger than the PRMSE $=.41$, Social Anxiety $=.35$ ). As recommended in Reise et al. (2013), the subscales were correlated (see Table 2) with each other and the total score, with coefficients ranging from .50 to .92 . Given these results combined the clinical utility of the focus of the subscale scores recognized by the scale authors (the importance of which is highlighted by Reise et al. in their discussion) scores were reported at both total and subscale level for the SAS-TR.

Parent-rated child anxiety. The Anxiety Scale for Children with Autism Spectrum Disorder Parent Form (ASC-ASD-P) (Rodgers et al., 2016) was available for 79 children in this sample. The ASC-ASD-P consists of 24 items from which four subscales have been derived: Performance Anxiety (five items; maximum score 15); Anxious Arousal (six items; maximum score 18); Separation Anxiety (five items; maximum score 15); and Uncertainty (eight items; maximum score 24). Severity was rated on a 4-point scale ranging from 0 (never) to 3 (always). Although the scale was originally developed for children aged 8 or above, it has been used in younger samples of children on the autism spectrum to describe anxiety symptomatology (e.g., 
Keen, Adams, Simpson, den Houting, \& Roberts, 2017). When exploring the data from the ASC-ASD-P collected from 170 parents of children on the autism spectrum, Rodgers et al. (2016) reported good convergent validity, test-retest reliability, and internal consistency and reported ASC-ASD-P total scores to be highly correlated with the Screen for Child Anxiety Related Emotional Disorders (SCARED) (Birmaher et al., 1999), a robust measure of anxiety in the general population. den Houting, Adams, Roberts and Keen (2018) also report on discriminate validity and concurrent validity against parent-reported anxiety diagnostic status. In the current study, internal consistency was identified as acceptable to excellent for all subscales based on Cronbach’s alpha, Anxious Arousal $\alpha=.82$, Separation Anxiety $\alpha=.79$, Performance Anxiety $\alpha=.91$, Uncertainty $\alpha=.83$, and excellent $(\alpha=.91)$ for the total score.

Given that both the ASC-ASD-P is a new and relatively unused measure and that the original factor analysis paper (Rodgers et al., 2016) did not report on subscale correlations, PRMSE values for each subscale were explore. For each subscale, the PRMSEs values (Anxious Arousal $\alpha=.82$, Separation Anxiety $\alpha=.79$, Performance Anxiety $\alpha=.91$, and Uncertainty $\alpha=.83$ ) were larger than the PRMSEтот values (Anxious Arousal $=.57$, Separation Anxiety $=.69$, Performance Anxiety $=.54$, and Uncertainty $=.60)$. As recommended in Reise et al. (2013), correlations between the subscales and total score were calculated and reported in Table 2, with coefficients ranging from .36 to .80 . Given these results combined with the clinical utility of the focus of the subscale scores, scores were reported at both total and subscale level for the ASC-ASD.

\section{Data analysis}


Data screening identified a non-normal distribution of the school anxiety scale total score and subscales. For this reason, coupled with the recognition that all measures are summed Likert data, non-parametric analyses were used throughout the study so as not to violate parametric assumptions.

First, in order to describe the symptoms reported by teachers in children with autism, the profile of the scores on the SAS-TR is presented graphically at item level. The proportions scoring above the clinical ("high-anxiety”) cut-offs were calculated and described for each cohort. Comparisons of total and subscale scores were made between children in the younger (5-7 years of age) and older (9-12 years of age) cohort, between males and females, and between those attending mainstream inclusive or special educational settings using a series of Mann-Whitney U tests. Effect sizes were reported in eta squared.

In order to explore the association between subscale scores on the school anxiety scale and parent-reported symptoms of anxiety, Spearman's correlations were conducted between the SAS-TR and the ASC-ASD subscales and total scores. In order to acknowledge the potential impact of the differing time between parent and teacher completion of the questionnaire, the correlations were repeated with time between completion as a covariate. Due to the large number of correlations within this study, $\alpha$ was set to .01 to interpret the correlational analysis in order to reduce the chance of a type I error. Finally, as four items between the parent and teacher reports of anxiety enquire about very similar symptoms, the level of agreement between parent and teacher reports was explored.

\section{Results}

\section{Profile of scores on the SAS-TR}


Children's scores on the SAS-TR ranged from 0-38 for the total score (maximum score 48) and 0-21 for both the generalized anxiety subscale (maximum score 27) and the social anxiety subscale (maximum score 21). The profile of scores for the total sample is shown in Figure 1, which highlights the items with the range of response patterns for each question, as well as allowing for identification of the items with the highest and lowest endorsement across the sample.

The three most frequently endorsed items were all in the generalized anxiety subscale, with almost one third (32.6\%) of children being rated as "often” or "always" hesitant in starting tasks or asking whether they understood the task before starting. More than a quarter of children "often” or "always” worry about things and are scared of making mistakes. Two of the three questionnaire items which had the lowest ratings $(<10 \%)$ on the "often” or "always" response options were within the social anxiety subscale.

Overall, 20 (21.7\%) children were above the cut-off for elevated anxiety on the total score on the SAS-TR, 13 of whom were from the older cohort. At subscale level, 25 (27.2\%) were above the cut-off on the generalized anxiety subscale (18 of whom were from the older cohort) and $13(14.1 \%)$ on the social anxiety subscale (seven of whom were from the older cohort). A large proportion (84.6\%) of children who scored above the cut-off for social anxiety also scored above the cut-off for generalized anxiety, but only $44 \%$ of those who scored above the cut-off for generalized anxiety also scored above the cut-off for social anxiety.

Of the small number $(n=8)$ who had a parent-reported diagnosis of anxiety, three scored above the generalized anxiety cut-off and two above the social anxiety cut-off. Four (50\%) of those with a parent-reported anxiety diagnosis did not have any scores above the cut-off on the SAS-TR. 


\section{Child characteristics and educational placement}

Table 1 summarizes the SAS-TR scores for the total sample and for the sample split by age group, gender, and educational placement. There were no significant differences between males and females on the total score or either of the subscales, although the effect size for the generalized anxiety subscale suggests a small effect size between males and females. There were significant differences between the younger and older cohorts and those attending mainstream and special educational settings on the generalized anxiety scale only, both with a small to medium effect size $\left(\eta^{2}=.06-.06\right)$. Although the Mann-Whitney U comparison was non-significant, there was a small effect size for the difference in total score between males and females $\left(\eta^{2}=.03\right)$ and the type of educational placement $\left(\eta^{2}=.03\right)$, which can be explained by the significant differences in the generalized anxiety items (which contribute to the total score).

\section{Associations between teacher- and parent-reported anxiety}

Table 2 summarizes the median scores for the parent ratings on the ASC-ASD, and the Spearman's correlations between teacher ratings on the SAS-TR and parent ratings on the ASC-ASD and SCQ. The results remained similar and there were no changes in the pattern of significant and non-significant results when the correlations were repeated with time between parent and teacher rating added as a covariate. The SCQ total score (as a measure of autism characteristics) was not correlated with SASTR scores. The social anxiety subscale did not correlate with any subscales or with the total score on the parent report of child anxiety. The SAS-TR generalized anxiety subscale was moderately correlated with the Performance Anxiety subscale ( $\rho=.52)$ and mildly correlated with the remaining subscales and total score $(\rho=.35-.48)$. 


\section{Item-level agreement between teacher- and parent-reported anxiety}

As four items between the parent and teacher rating scales are very similar, the level of parent-teacher agreement in ratings on items was explored and documented in Table 3. Table 3 highlights a relatively consistent pattern across these four items, with 49.4-51.9\% of parents and teachers agreeing on their ratings, which in the majority of cases (27.8-44.5\% of the sample) was due to both raters rating "never". Ratings made by parents were higher than those made by the child's teacher in 31.6$37.6 \%$ of the sample.

When looking across all four items, full parent-teacher agreement was noted in $13.9 \%$ of children, the majority of whom (10.1\% of the total sample) were in the special education group. Additionally, $16.5 \%$ of parents differed by only one point on one of the four questions (i.e., had total agreement on 3 questions and one point difference on the last question). There was a small but notable group (17.7\%) in which parent and teacher ratings differed by a total of 5-6 points across all the four items for children, the majority of whom (13.9\%) were in the mainstream group.

\section{Discussion}

The present study is novel in that it reports on a measure of school anxiety in a community sample of 92 children on the autism spectrum, and provides item-level data to describe the profile of school-related anxiety symptomatology in children on the autism spectrum. Using cut-offs suggested by Lyneham et al. (2008) which were derived from children with anxiety but no diagnosis of autism, teacher reports on the SAS-TR showed elevated levels of anxiety (above the total anxiety clinical cut-off) in $21.7 \%$ of the sample. A larger proportion of children scored above the generalized anxiety cut-off (27.2\%) than the social anxiety cut-off (14.1\%). 
One approach to understanding these prevalence levels is to compare them to those identified within the parent-report literature, although the SAS-TR has not been explored or validated in relation to other parent measures of anxiety in children with autism. The proportion of children within this study experiencing clinical levels of generalized anxiety within the school setting (27.2\%) was higher than the proportion previously reported in van Steensel et al.’s (2011) meta-analysis of 15\%. On the other hand, results for social anxiety in this study were similar to the $17 \%$ reported in the review by van Steensel et al. The van Steensel et al. analysis included only three studies with both parent and teacher reports, and only two of these contained teacher data on generalized and social anxiety, so the meta-analysis prevalence figures are largely based upon parent report. It is possible that the higher levels of generalized anxiety found in the current study reflect a specific pattern of anxiety symptomatology in the school context. Alternatively, they could be due to differences in measurement properties or cut-off scores for levels of clinical anxiety. Gadow, Devincent, Pomeroy, and Azizian (2005) reported similar teacher screening prevalence rates of $23.3 \%$ and $25.6 \%$ for generalized anxiety disorder and $13.8 \%$ and 9.8\% for social anxiety disorder across 284 6-12-year old males and females with pervasive developmental disorders, respectively. This suggests that one in four primary-school-aged children with autism are experiencing clinical levels of generalized anxiety at school. Thus the current study using the SAS-TR, and a previous study using the CSI-4 (Gadow et al., 2005), found higher than expected levels of generalised anxiety. Further research is needed to investigate generalized anxiety in primary-school-aged children on the autism spectrum using verified anxiety-specific measures and multiple informants. 
The study aimed to describe the profile of school-related anxiety symptomatology in students with autism. The symptoms most frequently rated as “often” or “always” were worrying about things (27.2\%), being afraid of making mistakes (27.2\%), and hesitating in starting tasks or when asked whether they understood the task before starting (32.6\%). In contrast, very few children were “often” or "always” reported to be afraid to ask questions in class (7.7\%), to speak in group situations (8.7\%), or to feel shaky when they have a problem (8.7\%). Implementing evidence-based interventions into real-world settings (such as the classroom) has been identified as a key priority for anxiety research (Vasa, Keefer, Reaven, South, \& White, 2018). Knowing the most common anxiety symptomatology within this population in the classroom setting can inform the development of targeted interventions for the school setting specifically tailored for individuals on the autism spectrum, an area highlighted as a key need by South, Rodgers, and Van Hecke (2017).

Participants in the older cohort (aged 9-12) and those attending mainstream schools had significantly higher scores on the generalized, but not the social, anxiety subscales, with effect sizes suggesting a medium effect. In relation to age, associations between chronological age and anxiety have been reported in the literature, although the direction of this association has varied depending on the measures used and the type of anxiety studied (Magiati et al., 2015). In their metaanalysis, van Steensel et al. (2011) noted that generalized anxiety was higher in older children, consistent with our findings, whereas separation anxiety and obsessivecompulsive disorder were more common in younger children. With respect to higher generalized anxiety for children in mainstream settings, teachers may have been rating individuals "relative" to their expectations and experiences for children on the 
autism spectrum. That is, there may have been some diagnostic overshadowing impacting upon teacher ratings for questions in the SAS-TR social anxiety subscale, as the total score was 1 or below for more than a quarter of children in the total sample, rising to more than one third for children within a special educational setting. Social anxiety is diagnostically distinct from more generalized anxiety, in that the anxiety is specific to social interactions with known and unknown individuals (see Gadow \& Sprafkin, 2002); there are discussions in the literature as to the accuracy of identifying symptoms of social anxiety in individuals on the autism spectrum (see Pellecchia et al., 2016), particulartly in the presence of an intellectual disability, an area that is significantly underresearched (Adams \& Oliver, 2011; Flynn et al., 2017).

The lack of significant difference in total or subscale SAS-TR scores between the gender subgroups aligns with the autism-specific (e.g., May, Cornish, \& Rinehart, 2014) and typically developing anxiety literature (e.g., Lyneham et al., 2008). Gender differences in anxiety scores are more frequently noted in self-report studies (e.g., Spence, 1998), but are less frequently noted in informant studies. It is possible that the diagnostic overshadowing discussed above is further compounded by the factor of gender (Lyneham et al., 2008) and also the expectations of a boy or girl on the spectrum.

The very weak to weak correlations between teacher and parent ratings of anxiety noted within this study reflect those reported in the literature (e.g., Kanne et al., 2009). Interestingly, two of the parent-teacher correlations were stronger than those typically reported: teacher general anxiety score with parent total score (.48) and performance anxiety (.52). The performance anxiety subscale only contains one out of the four overlapping questions between the two measures, so this higher correlation cannot simply be explained by having a higher proportion of identical 
questions. It may be that the focus of the items in the ASC-ASD-P performance subscale (e.g., doing badly at school work, taking tests, what others may think or feel) are more relevant or obvious to the school context than, for example, those in the ASC-ASD-P uncertainty subscale (e.g., entering crowded environments, needing to be prepared and informed before things happen) due to the structure of the school setting. This highlights the importance of studies, especially intervention studies, gathering information from multiple informants across multiple settings, as the context is very likely to impact upon the triggers and presentation of an individual's anxiety (Adams, Young, Simpson \& Keen, 2018). Taking the perspective recommended by De Los Reyes et al. (2015), each informant is a potentially important source of information about how context, settings, and other factors may influence the experience or presentation of an individual's mental health and behavior, information that may be helpful when trying to understand an individual's presentation and when planning interventions.

Although the parent-teacher report correlations were low to moderate, when the parent-teacher scores for the four overlapping items between the SAS-TR and the ASC-ASD-P are compared at an individual child and item level (rather than a group mean), parents and teachers agree on the frequency of symptoms $50.8 \%$ of the time (ranging from $49.4 \%$ to $51.9 \%$ across the four questions). This most commonly occurred when the ratings were "never" from both the parent and the teacher (27.8$44.3 \%$ of cases). In addition, $88.7 \%$ of respondents either agreed or were within one point of the other respondent on that specific question. This emphasizes the importance of using comparable measures for each informant and considering the importance of scaling when interpreting levels of agreement. Although both the SASTR and the ASC-ASD-P are anxiety measures, the majority of behaviors (as signs of 
anxiety) that parents or teachers are scoring on differ. This means that even if setting and context had no impact upon the experience or presentation of anxiety, some differences between informant/scale scores would be expected. This identifies the need to work towards measures with comparable multi-informant versions to gather reliable data on similarities and differences across settings and contexts.

\section{Strengths, limitations, and future directions}

This study is one of the few to explore anxiety symptomatology in a community sample of children on the autism spectrum using an anxiety-specific measure completed by teachers as informants. Analysis at the item level has provided a comprehensive description of anxiety presentation in the school context. Further, the inclusion of parent-reported anxiety using the ASC-ASD has highlighted similarities and differences across the home and school context and the importance of multiple informants when examining anxiety in autism.

Nevertheless, the study needs to be considered in relation to its limitations. The comparisons between gender, age group and educational placement need to be interpreted with caution due to the small sample size limiting assessment of measurement invariance between groups. The sample size in the group comparisons may also have resulted in insufficient power to detect additional group differences. The SAS-TR and ASC-ASD are also relatively unused measures of anxiety symptomatology and would benefit further exploration of the possible factor structure (and in the case of the SAS-TR, if this is applicable for children on the autism spectrum). There may also have been an ascertainment bias in the study, as the parents who participated were those who were motivated to take part and share their child's school details, and then the teachers who participated were those who were motivated to complete a questionnaire. A community diagnosis of autism was 
confirmed by diagnostic reports and a score above the cut-off on a widely accepted and validated measure of autism characteristics. Due to the study design, however, no direct testing was conducted. The addition of a diagnostic tool such as the Autism Diagnostic Observation Schedule, together with measures of cognitive functioning and classroom observations to complement teacher responses on the SAS-TR, would extend the research and increase our understanding of anxiety at school.

It will be important for future studies to build upon this work, collecting data from multiple informants with larger samples across a broader age range. This would allow for further exploration of the relatively new measures used within this paper (ASC-ASD and SAS-TR) and undertake a Confirmatory Factor Analysis and explore the degree to which the subscale scores reflect a construct that is unique from the construct that is represented by the total score. This is especially important for the SAS-TR, given the strong (>.9) correlation between the generalised anxiety score and the total score noted within this sample. Larger samples would also allow for further examination of factors such as gender and educational setting across different time points (e.g., early childhood, adolescence) . Collecting data from self-report measures from those who are old enough and/or able to complete them to create a triad of perspectives would also help in understanding the role of the environment and context in the presentation of anxiety. Using the item-level inter-informant agreement method adopted within this study will be important to understand if and how the clinical picture of anxiety changes for children on the autism spectrum across settings. As this study is cross-sectional, it does not allow for comment on the course or progression of the outcomes explored. Longitudinal studies tracking children through to adolescence and adulthood will be important in understanding how differing school 
contexts and milestones, such as transitions, may impact upon teacher-reported anxiety levels. 


\section{Acknowledgements}

We thank the parents and teachers who participated in this study for the time and commitment in completing the questionnaires. The authors also acknowledge the work of the LASA team members: Jacqui Roberts (Project Leader), Susan Bruck, Trevor Clark, Sandra Devaraj, Robyn Garland, Honey Heussler, Antoinette Hodge, Patricia Howlin, Jessica Paynter, Natalie Silove, David Trembath, Madonna Tucker, Marleen Westerveld, Katrina Williams. The financial support of the Cooperative Research Centre for Living with Autism (Autism CRC; project 2.007), established and supported under the Australian Government's Cooperative Research Centres Program, is also acknowledged. 


\section{References}

Achenbach, T. M., McConaughy, S. H., \& Howell, C. T. (1987). Child/adolescent behavioral and emotional problems: Implications of cross-informant correlations for situational specificity. Psychological Bulletin, 101, 213-232.

Adams, D., \& Oliver, C. (2011). The expression and assessment of emotions and internal states in individuals with severe or profound intellectual disabilities. Clinical Psychology Review, 31, 293-306. doi:10.1016/j.cpr.2011.01.003

Adams, D., Young, K., Simpson, K. \& Keen, D. (2018). Parent descriptions of the presentation and management of anxiousness in children on the autism spectrum. Autism.

Allen, J. L., \& Lerman, R. (2017). Teacher Responses to Anxiety in Children Questionnaire (TRAC): Psychometric properties and relationship with teaching staff characteristics. Emotional and Behavioural Difficulties. doi:10.1080/13632752.2017.1376974

American Psychiatric Association. (2013). Diagnostic and statistical manual of mental disorders (5th ed.). Arlington, VA: American Psychiatric Publishing.

Ashburner, J., Ziviani, J., \& Rodger, S. (2010). Surviving in the mainstream: Capacity of children with autism spectrum disorders to perform academically and regulate their emotions and behavior at school. Research in Autism Spectrum Disorders, 4, 18-27. doi: 10.1016/j.rasd.2009.07.002

Beesdo, K., Knappe, S., \& Pine, D. (2009). Anxiety and anxiety disorders in children and adolescents: Developmental issues and implications for DSM-V. Psychiatric Clinics of North America, 32, 483-524. doi:10.1016/j.psc.2009.06.002. 
Birmaher, B., Brent, D., Chiapetta, L., Bridge, J., Monga, S., \& Baugher, M. (1999). Psychometric properties of the screen for child anxiety related emotional disorders (SCARED): A replication study. Journal of the American Academy of Child \& Adolescent Psychiatry, 38, 1230-1236. doi:10.3758/s13421-012$0272-7$

Centers for Disease Control and Prevention. (2014). Prevalence of autism spectrum disorders among children aged 8 years - autism and developmental disabilities monitoring network, 11 sites, United States, 2010. Morbidity and Mortality Weekly Report. Surveillance Summaries, 63, 1-21.

Chang, Y. C., Quan, J., \& Wood, J. J. (2012). Effects of Anxiety Disorder Severity on Social Functioning in Children with Autism Spectrum Disorders. Journal of Developmental and Physical Disabilities, 24, 235-245. doi:10.1007/s10882012-9268-2

Chesnut, S. R., Wei, T., Barnard-Brak, L., \& Richman, D. M. (2016). A meta-analysis of the social communication questionniare: Screening for autism spectrum disorder. Autism: The International Journal of Research and Practice, 21, 920-928. doi:10.1177/1362361316660065

De Los Reyes, A., Augenstein, T. M., Wang, M., Thomas, S. A., Drabick, D. A. G., Burgers, D. E., \& Rabinowitz, J. (2015). The validity of the multi-informant approach to assessing child and adolescent mental health. Psychological Bulletin, 141, 858-900. doi:10.1037/a0038498

De Los Reyes, A., \& Kazdin, A. E. (2005). Informant discrepancies in the assessment of childhood psychopathology: A critical review, theoretical framework, and recommendations for further study. Psychological Bulletin, 131, 483-509. doi: 10.1037/0033-2909.131.4.483 
den Houting, J., Adams, D., Roberts, J., \& Keen, D. (2018). Exploring anxiety symptomatology in school-aged autistic children using an autism-specific assessment. Research in Autism Spectrum Disorders, 50, 73-82. doi:10.1016/j.rasd.2018.03.005

Einfeld, S., \& Tonge, B. J. (2002). Developmental behaviour checklist. Sydney: University of New South Wales and Monash University.

Ferraioli, S. J., \& Harris, S. L. (2011). Effective educational inclusion of students on the autism spectrum. Journal of Contemporary Psychotherapy, 41, 19-28. doi: 10.1007/s10879-010-9156-y

Flynn, S., Vereenooghe, L., Hastings, R. P., Adams, D., Cooper, S. A., Gore, N., . . . Waite, J. (2017). Measurement tools for mental health problems and mental well-being in people with severe or profound intellectual disabilities: A systematic review. Clinical Psychology Review, 57, 32-44. doi:10.1016/j.cpr.2017.08.006

Fujii, C., Renno, P., McLeod, B. D., Lin, C. E., Decker, K., Zielinski, K., \& Wood, J. J. (2013). Intensive cognitive behavioral therapy for anxiety disorders in school-aged children with autism: A preliminary comparison with treatmentas-usual. School Mental Health, 5, 25-37. doi: 10.1007/s12310-012-9090-0

Gadow, K. D., Devincent, C. J., Pomeroy, J., \& Azizian, A. (2005). Comparison of DSM-IV symptoms in elementary school-age children with PDD versus clinic and community samples. Autism: The International Journal of Research and Practice, 9, 392-415. doi: 10.1177/1362361305056079

Gadow, K. D., \& Sprafkin, J. (2002). Child symptom inventory 4. Stony Brook, NY: Checkmate Plus. 
Goodman, R. (1997). The Strengths and Difficulties Questionnaire: A research note. Journal of Child Psychology and Psychiatry, 38, 581-586. doi: 10.1111/j.1469-7610.1997.tb01545.x

Guttmann-Steinmetz, S., Gadow, K. D., DeVincent, C. J., \& Crowell, J. (2010). Anxiety symptoms in boys with autism spectrum disorder, attention-deficit hyperactivity disorder, or chronic multiple tic disorder and community controls. Journal of Autism and Developmental Disorders, 40, 1006-1016. doi: 10.1007/s10803-010-0950-x

Haberman, S. J. (2008). When can subscores have value? Journal of Educational and Behavioral Statistics, 33, 204-229. doi: 10.3102/1076998607302636

Hebron, J., \& Humphrey, N. (2014). Exposure to bullying among students with autism spectrum conditions: A multi-informant analysis of risk and protective factors. Autism, 18, 618-630. doi:10.1177/1362361313495965

Herzig-Anderson, K., Colognori, D., Fox, J. K., Stewart, C. E., \& Masia Warner, C. (2012). School-based anxiety treatments for children and adolescents. Child and Adolescent Psychiatric Clinics, 21, 655-668. doi:

10.1016/j.chc.2012.05.006

Hoyt, W. T. (2000). Rater bias in psychological research: When is it a problem and what can we do about it? Psychological Methods, 5, 64-86. doi: 10.1037//1082 989X.5.1.64

Johnston, K. H. S., \& Iarocci, G. (2017). Are Generalized Anxiety and Depression Symptoms Associated with Social Competence in Children with and without Autism Spectrum Disorder? Journal of Autism and Developmental Disorders, 47, 3778-3788. doi:10.1007/s10803-017-3056-x

Kanne, S. M., Abbacchi, A. M., \& Constantino, J. N. (2009). Multi-informant ratings of psychiatric symptom severity in children with autism spectrum disorders: 
The importance of environmental context. Journal of Autism and Developmental Disorders, 39, 856-864. doi: 10.1007/s10803-009-0694-7

Keen, D., Adams, D., Simpson, K., den Houting, J., \& Roberts, J. (2017). Anxietyrelated symptomatology in young children on the autism spectrum. Autism. doi:10.1177/1362361317734692

Kenny, L., Hattersley, C., Molins, B., Buckley, C., Povey, C., \& Pellicano, L. (2016). Which terms should be used to describe autism? Perspectives from the UK autism community. Autism, 20, 442-462. doi: 10.1177/1362361315588200

Kraemer, H. C., Measelle, J. R., Ablow, J. C., Essex, M. J., Boyce, W. T., \& Kupfer, D. J. (2003). A new approach to integrating data from multiple informants in psychiatric assessment and research: Mixing and matching contexts and perspectives. American Journal of Psychiatry, 160, 1566-1577. doi: 10.1176/appi.ajp.160.9.1566

Kuusikko, S., Pollock-Wurman, R., Jussila, K., Carter, A. S., Mattila, M. L., Ebeling, H., . . . Moilanen, I. (2008). Social anxiety in high-functioning children and adolescents with Autism and Asperger syndrome. Journal of Autism and Developmental Disorders, 38, 1697-1709. doi:10.1007/s10803-008-0555-9

Langley, A. K., Bergman, L. R., McCracken, J., \& Piacentini, J. C. (2004). Impairment in childhood anxiety disorders: A preliminary examination of the child anxiety impact scale-parent version. Journal of Child and Adolescent Psychopharmacology, 14, 105-114. doi: 10.1089/104454604773840544

Lee, L., David, A. B., Rusyniak, J., Landa, R., \& Newschaffer, C. J. (2007). Performance of the social communication questionnaire in children receiving preschool special education services. Research in Autism Spectrum Disorders, 1, 126-138. doi: 10.1016/j.rasd.2006.08.004 
Luxford, S., Hadwin, J. A., \& Kovshoff, H. (2016). Evaluating the effectiveness of a school-based cognitive behavioural therapy intervention for anxiety in adolescents diagnosed with autism spectrum disorder. Journal of Autism and Developmental Disorders, 47, 3896-3908. doi: 10.1007/s10803-016-2857-7

Lyneham, H. J., Street, A. K., Abbott, M. J., \& Rapee, R. M. (2008). Psychometric properties of the school anxiety scale - teacher report (SAS-TR). Journal of Anxiety Disorders, 22, 292-300. doi: 10.1016/j.janxdis.2007.02.001

Ma, X. (1999). A meta-analysis of the relationship between anxiety toward mathematics and achievement in mathematics. Journal for Research in Mathematics Education, 30, 520-540.

Magiati, I., Ong, C., Lim, X., Tan, J., Ong, A., Patrycia, F., . . Howlin, P. (2015). Anxiety symptoms in young people with autism spectrum disorder attending special schools: Association with gender, adaptive functioning and autism symptomatology. Autism, 20, 306-320. doi:10.1177/1362361315577519

May, T., Cornish, K., \& Rinehart, N. (2014). Does gender matter? A one year followup of autistic, attention and anxiety symptoms in high-functioning children with autism spectrum disorder. Journal of Autism and Developmental Disorders, 44, 1077-1086. doi: 10.1007/s10803-013-1964-y

Mychailyszyn, M. P., Mendez, J. L., \& Kendall, P. C. (2010). School functioning in youth with and without anxiety disorders: Comparisons by diagnosis and comorbidity. School Psychology Review, 39, 106-121.

Pellecchia, M., Connell, J. E., Kerns, C. M., Xie, M., Marcus, S. C., \& Mandell, D. S. (2016). Child characteristics associated with outcome for children with autism in a school-based behavioral intervention. Autism: The International Journal of Research and Practice, 20, 321-329. doi:10.1177/1362361315577518 
Polanczyk, G. V., Salum, G. A., Sugaya, L. S., Caye, A., \& Rohde, L. A. (2015). Annual research review: A meta-analysis of the worldwide prevalence of mental disorders in children and adolescents. Journal of Child Psychology and Psychiatry, 56, 345-365. doi:10.1111/jcpp.12381

Reise, S.P., Bonifay, W.E., \& Haviland, M.G. (2013). Scoring and Modeling Psychological Measures in the Presence of Multidimensionality. Journal of Personality Assessment, 95, 1291240. doi:10.1080/00223891.2012.725437

Roberts, J., \& Simpson, K. (2016). A review of research into stakeholder perspectives on inclusion of students with autism in mainstream schools. International Journal of Inclusive Education, 20, 1084-1096. doi:10.1080/13603116.2016.1145267

Roberts, J. Adams, D., Heussler, H., Keen, D., Paynter, J., Trembath, D., Westerveld, M. \& Williams, K. (2018). Protocol for a prospective longitudinal study investigating the participation and educational trajectories of Australian students with autism. BMJ Open, 8, e017082.

Rodgers, J., Wigham, S., McConachie, H., Freeston, M., Honey, E., \& Parr, J. R. (2016). Development of the anxiety scale for children with autism spectrum disorder (ASC-ASD): Measuring anxiety in ASD. Autism Research, 9, 12051215. doi:10.1002/aur.1603

Rutter, M., Bailey, A., Lord, C., \& Berument, S. K. (2003). Social Communication Questionnaire. Los Angeles, CA: Western Psychological Services.

Simonoff, E., Pickles, A., Charman, T., Chandler, S., Loucas, T., \& Baird, G. (2008). Psychiatric disorders in children with autism spectrum disorders: prevalence, comorbidity, and associated factors in a population-derived sample. Journal of 
the American Academy of Child and Adolescent Psychiatry, 47, 921-929. doi:10.1097/CHI.0b013e318179964f

South, M., Rodgers, J., \& Van Hecke, A. (2017). Anxiety and ASD: Current progress and ongoing challenges. Journal of Autism and Developmental Disorders, 47, 3679-3681. doi: 10.3389/fnhum.2017.00020

Sparrow, S., Cicchetti, D., \& Balla, D. (2005). Vineland-II. Vineland Adaptive Behavior Scales (2 ed.). Bloomington, MN: Pearson.

Spence, S. H. (1998). A measure of anxiety symptoms among children. Behaviour Research and Therapy, 36, 545-566.

Stratis, E. A., \& Lecavalier, L. (2015). Informant agreement for youth with autism spectrum disorder or intellectual disability: A meta-analysis. Journal of Autism and Developmental Disorders, 45, 1026-1041. doi: 10.1007/s10803$014-2258-8$

van Steensel, F. J., Bogels, S. M., \& Perrin, S. (2011). Anxiety disorders in children and adolescents with autistic spectrum disorders: A meta-analysis. Clinical Child and Family Psychology Review, 14, 302-317. doi:10.1007/s10567-0110097-0

Vasa, R. A., Keefer, A., Reaven, J., South, M., \& White, S. W. (2018). Priorities for advancing research on youth with autism spectrum disorder and co-occurring anxiety. Journal of Autism and Developmental Disorders, 48, 925-934. doi:10.1007/s10803017-3320-0

Weisbrot, D. M., Gadow, K. D., DeVincent, C. J., \& Pomeroy, J. (2005). The presentation of anxiety in children with pervasive developmental disorders. Journal of Child and Adolescent Psychopharmacology, 15, 477-496. doi: 10.1089/cap.2005.15.477 
Weissman, A., Antinoro, D., \& Chu, B. (2009). Cognitive-behavioral therapy for anxious youth in school settings. Advances and challenges. In M. Mayer, R. Van Acker, J. Lochman, \& F. Gresham (Eds.), Cognitive-behavioral interventions for emotional and behavioral disorders: School based practice (pp. 173-203). New York: Guilford Press. 


\section{$\square$ Never $\square$ Sometimes $\square$ Often $\square$ Always}

Child afraid of asking questions in class

Child speaks only when someone asks a question of them

Child worries what other people think of him/her

Child does not volunteer answers or comments during class

Child is afraid of making mistakes Child hates being the centre of attention

Child hesitates in starting tasks or asks whether they understood the task before starting

Child worries about things

Child worries that (s)he will do badly at school

Child worries that something bad will happen to him/her

Child seems very shy

Child complains of headaches, stomach aches or feeling sick

Child feels afraid when (s)he has to talk in front of the class

Child hesitates to speak when in group situations

When the child has a problem, (s)he feels shaky

Child appears nervous when approached by other children or adults

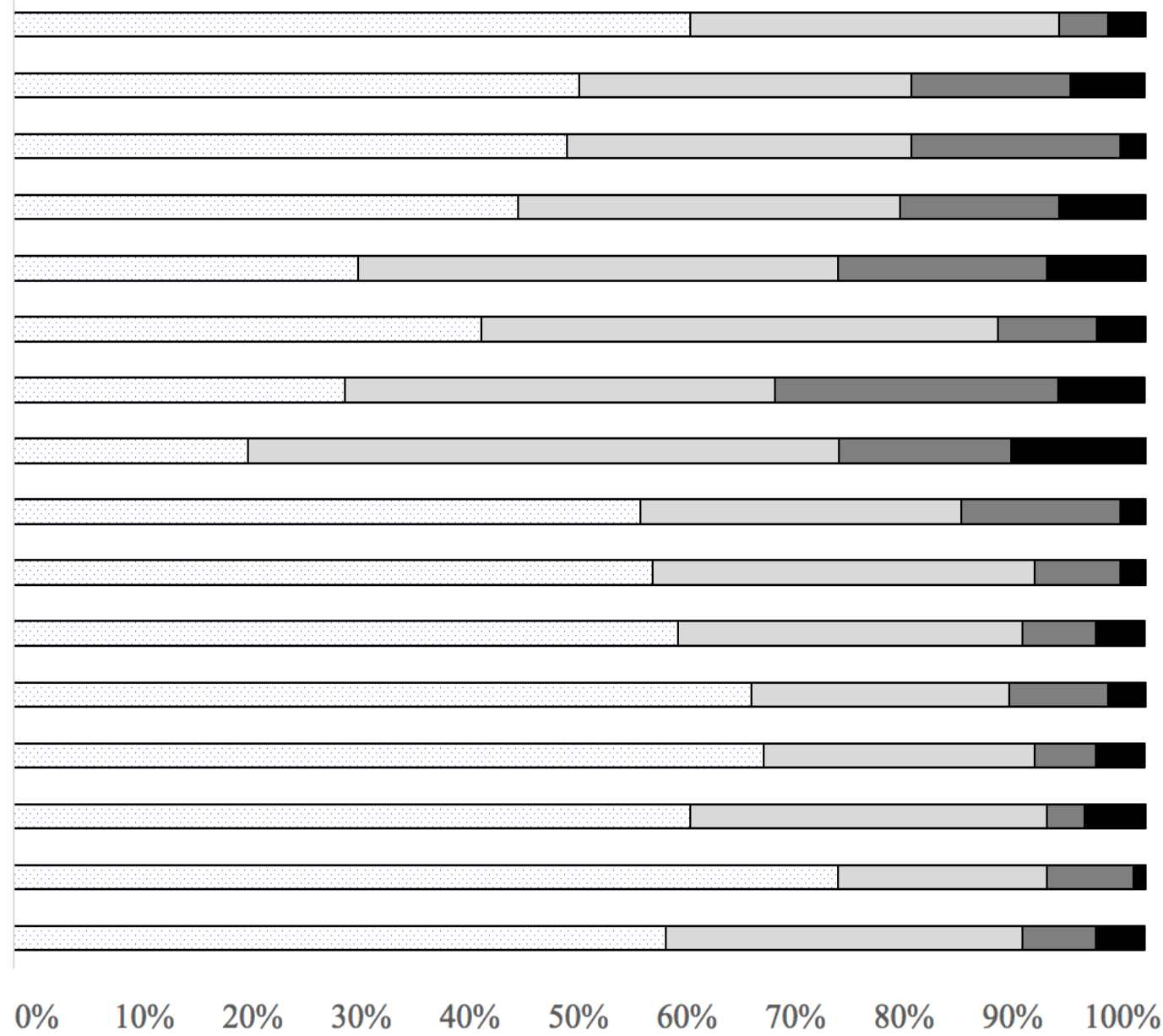

Figure 1. Profile of scores for the total sample on the SAS-TR. 


\section{Table 1}

Median (IQR) SAS-TR Total and Subscale Score for the Total Sample and Comparisons by Age Cohort, Gender, and Educational Placement

\begin{tabular}{|c|c|c|c|c|c|c|c|c|c|c|}
\hline & \multirow{2}{*}{$\begin{array}{c}\text { Total } \\
\text { Sample } \\
(n=92)\end{array}$} & \multicolumn{3}{|c|}{ Age cohort } & \multicolumn{3}{|c|}{ Gender } & \multicolumn{3}{|c|}{ Educational placement } \\
\hline & & $\begin{array}{l}\text { Younger } \\
(n=41)\end{array}$ & $\begin{array}{l}\text { Older } \\
(n=51)\end{array}$ & $\begin{array}{c}\text { Mann- } \\
\text { Whitney U } \\
\text { Comparison }\end{array}$ & $\begin{array}{c}\text { Male } \\
(n=74)\end{array}$ & $\begin{array}{l}\text { Female } \\
(n=18)\end{array}$ & $\begin{array}{c}\text { Mann- } \\
\text { Whitney U } \\
\text { Comparison }\end{array}$ & $\begin{array}{c}\text { Mainstream } \\
\text { inclusive } \\
(n=62)\end{array}$ & $\begin{array}{c}\text { Special } \\
\text { education } \\
(n=30)\end{array}$ & $\begin{array}{c}\text { Mann- } \\
\text { Whitney U } \\
\text { Comparison }\end{array}$ \\
\hline SAS-TR Total & $\begin{array}{c}9.5 \\
(7.75)\end{array}$ & $\begin{array}{c}9 \\
(7.5)\end{array}$ & $\begin{array}{c}11 \\
(10)\end{array}$ & $\begin{array}{c}U=853.5 \\
p=.13 \\
\eta^{2}=.03\end{array}$ & $\begin{array}{c}10 \\
(7.5)\end{array}$ & $\begin{array}{c}7.5 \\
(11.75)\end{array}$ & $\begin{array}{c}U=573.5 \\
p=.36 \\
\eta^{2}=.01\end{array}$ & $\begin{array}{c}11 \\
(7.25)\end{array}$ & $\begin{array}{c}7.5 \\
(9.25)\end{array}$ & $\begin{array}{c}U=736 \\
p=.11 \\
\eta^{2}=.03\end{array}$ \\
\hline $\begin{array}{l}\text { SAS-TR Generalized } \\
\text { anxiety }\end{array}$ & $\begin{array}{l}5.5 \\
(7)\end{array}$ & $\begin{array}{c}4 \\
(5.5)\end{array}$ & $\begin{array}{c}7 \\
(7)\end{array}$ & $\begin{array}{l}U=744 \\
p=.02 \\
\eta^{2}=.06\end{array}$ & $\begin{array}{c}6 \\
(6)\end{array}$ & $\begin{array}{c}4.5 \\
(5.5)\end{array}$ & $\begin{array}{l}U=509 \\
p=.12 \\
\eta^{2}=.03\end{array}$ & $\begin{array}{c}6 \\
(6.25)\end{array}$ & $\begin{array}{c}4 \\
(6.75)\end{array}$ & $\begin{array}{c}U=661 \\
p=.02 \\
\eta^{2}=.06\end{array}$ \\
\hline $\begin{array}{l}\text { SAS-TR Social } \\
\text { anxiety }\end{array}$ & $\begin{array}{c}4 \\
(5)\end{array}$ & $\begin{array}{c}4 \\
(5.5)\end{array}$ & $\begin{array}{c}4 \\
(5)\end{array}$ & $\begin{array}{c}U=1017 \\
p=.82 \\
\eta^{2}<.001\end{array}$ & $\begin{array}{c}4 \\
(4.25)\end{array}$ & $\begin{array}{c}4 \\
(5.25)\end{array}$ & $\begin{array}{c}\mathrm{U}=644.5 \\
p=.83 \\
\eta^{2}<.001\end{array}$ & $\begin{array}{c}4 \\
(4)\end{array}$ & $\begin{array}{c}4 \\
(3)\end{array}$ & $\begin{array}{l}U=929 \\
p=.99 \\
\eta^{2}<.001\end{array}$ \\
\hline
\end{tabular}


Table 2

Spearman's Correlations between Teacher and Parent Measures of Child Anxiety with Median (IQR) Scores for ASC-ASD and SCQ

\begin{tabular}{|c|c|c|c|c|c|c|c|c|c|c|c|}
\hline & & \multirow[b]{2}{*}{ Median (IQR) } & \multicolumn{6}{|c|}{ Parent ASC-ASD and SCQ } & \multicolumn{3}{|c|}{ Teacher SAS-TR } \\
\hline & & & 1 & 2 & 3 & 4 & 5 & 6 & 7 & 8 & 9 \\
\hline \multirow{6}{*}{ 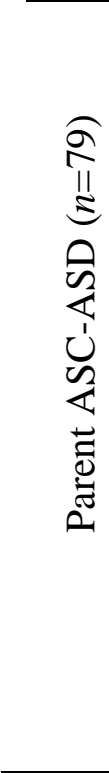 } & 1. Total score (24 items) & $\begin{array}{c}21 \\
(19)\end{array}$ & - & $.74 * *$ & $.77^{* *}$ & $.80 * *$ & $.80 * *$ & .07 & $.39 * *$ & $.48^{* *}$ & .11 \\
\hline & 2. Performance anxiety (5 items) & $\begin{array}{c}4 \\
(8)\end{array}$ & & - & $.53 * *$ & $.50 * *$ & $.36^{*}$ & -.07 & $.38 * *$ & $.52 * *$ & .03 \\
\hline & 3. Anxious arousal (6 items) & $\begin{array}{c}2 \\
(5)\end{array}$ & & & - & $.57 * *$ & $.52 * *$ & .14 & $.34 *$ & $.36^{* *}$ & .15 \\
\hline & 4. Separation anxiety (5 items) & $\begin{array}{c}4 \\
(5)\end{array}$ & & & & - & $.63 * *$ & .06 & $.31 *$ & $.38 * *$ & .09 \\
\hline & 5. Uncertainty (8 items) & $\begin{array}{c}10.5 \\
(7)\end{array}$ & & & & & - & .08 & $.30 *$ & $.35^{*}$ & .09 \\
\hline & 6. Total SCQ score & $\begin{array}{l}23 \\
(9)\end{array}$ & & & & & & - & .050 & .05 & .10 \\
\hline \multirow{3}{*}{ 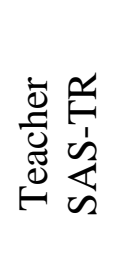 } & 7. Total Score & & & & & & & & - & $.92 * *$ & $.78^{* *}$ \\
\hline & 8. General Anxiety & & & & & & & & & - & $.50 * *$ \\
\hline & 9. Social Anxiety & & & & & & & & & & - \\
\hline
\end{tabular}


Table 3

Difference between Scores on Similar Items between Parent-Completed ASC-ASD and Teacher-Completed SAS-TR

Difference in scores (\% of participants)

Positive score reflects higher rating by parent on ASC-ASD, negative reflects higher rating by teacher on SAS-TR,

Zero reflects agreement on rating between parent and teacher

$\begin{array}{lllllll}-3 & -2 & -1 & 0 & 1 & 2 & 3\end{array}$

ASCASD Q1 "My child worries what other people think of him/her e.g., that he/ she is different”- SAS-TR Q3 “The child worries what other people think of him/her"

3.8

$8 \quad 11.4$

51.9

24.1

ASCASD Q7 "My child worries about doing badly at school work" -

SAS-TR Q9 “This child worries (s)he will do badly at school”

$1.3 \quad 11.3$

50.0

28.8

ASCASD Q24 "My child worries that something bad will happen to him/her" SAS-TR Q10 "This child worries that something bad will happen to him/her"

ASCASD Q12 "When my child has a problem, he/she feels shaky" SAS-TR Q15 "When this child has a problem, (s)he feels shaky” 
